\title{
ESTUDO DA CAPACIDADE DE INFILTRAÇÃO EM SISTEMAS DE RECARGA ARTIFICIAL DE AQUÍFEROS CONTAMINADOS NO DISTRITO FEDERAL
}

\author{
STUDY OF INFILTRATION CAPACITY IN ARTIFICIAL RECHARGE SYSTEMS FOR \\ CONTAMINATED AQUIFERS IN THE FEDERAL DISTRICT
}

\author{
Maria Dulcinea Xavier NUNES ${ }^{1}$, José Eloi Guimarães CAMPOS ${ }^{2}$ \\ ${ }^{1}$ Departamento de Estradas de Rodagem, Setor SAM Bloco C, Setores Complementares. Brasília, DF - Brasil \\ Email: mdxnunes@yahoo.com.br \\ ${ }^{2}$ Instituto de Geociências, Universidade de Brasília, Campus Universitário Darcy Ribeiro, Asa Norte. Brasília, DF- Brasil. \\ Email: eloi@unb.br \\ Introdução \\ Materiais E Métodos \\ Resultados \\ Avaliação da Contaminação dos Aquíferos \\ Capacidade Máxima de Infiltração Projeto Piloto I \\ Tempo de Chegada das Águas \\ Cálculo dos Volumes Estimados de Recarga Artificial Potencial no Condomínio San Diego \\ Cálculo dos Volumes Estimados de Recarga Artificial Potencial no Condomínio Privê \\ Estimativas de Reservas Renováveis e Permanentes \\ Reservas Renováveis - Projeto Piloto I \\ Reservas Renováveis - Projeto Piloto II \\ Reservas Permanentes \\ Análise Qualitativa dos Resultados \\ Análise Quantitativa dos Resultados \\ Considerações Finais \\ Referências
}

\begin{abstract}
RESUMO - O presente estudo objetivou aplicar técnicas de recarga artificial de aquíferos para minimizar os efeitos da contaminação de aquíferos por infiltração de efluentes domésticos. O sistema piloto testado utilizou água injetada em caixas de recarga cilíndricas, com um metro de diâmetro, preenchidas por cascalho quartzoso lavado (seixos de quartzito e quartzo). Os resultados obtidos mostram que: 1) os sistemas pilotos aplicados apresentam alta efetividade para induzir a infiltração de águas de chuvas coletadas nas coberturas de edificações em condomínios horizontais; 2) os volumes potenciais de infiltração, considerando diferentes cenários, são relevantes e podem auxiliar na remediação in situ de aquíferos contaminados em prazos variáveis entre 5 e 15 anos dependendo do grau de adesão da população e do meio físico local; 3) a eficiência da recarga artificial pode ser quantificada pela capacidade máxima de infiltração nos diferentes sistemas de recarga e varia conforme os diferentes controles do meio físico local, 4) a região do Condomínio San Diego já tem aquíferos contaminados pela infiltração dos efluentes, 5) a contaminação foi constatada pelo monitoramento da qualidade das águas dos poços de abastecimento e pela presença de nitrato e amônia nas águas das nascentes que são exutórios destes aquíferos.

Palavras-chave: recarga artificial, capacidade de infiltração, aquífero contaminado.
\end{abstract}

ABSTRACT - The objective of the present study is the application of aquifers artificial recharge techniques to minimize the effects of groundwater contamination by infiltration of domestic effluents. The pilot system tested the water injection in cylindrical, recharge digs with on meter diameter, filled with washed river gravel (quartzite pebble). The main results show that: 1) the proposed artificial recharge systems show high effectiveness to induce infiltration of rainwater collected on roofs of buildings into the soil and deep aquifers; 2) potential infiltration volumes, considering different scenarios are relevant and can assist in-situ remediation of contaminated aquifers in periods between 5 to 15 years, depending on the degree of population compliance and the local environment (soil, declivity and geology); 3) the efficiency of artificial recharge can be quantified by the maximum capacity of infiltration in different recharge systems and varies according to the different local controls, 4) the aquifers of the San Diego Condominium are already contaminated by leakage of wastewater, 5) the contamination was established by monitoring water quality of supply wells and the presence of nitrate and ammonia in springs that represent discharge areas of these aquifers.

Keywords: artificial recharge, infiltration capacity, contaminated aquifer.

\section{INTRODUÇÃO}

Esta pesquisa foi desenvolvida em duas áreas residenciais na porção central do Distrito Federal: denominados condomínios Privê do Lago Norte e San Diego. O Distrito Federal está localizado na região Centro Oeste do país, na região geográfica do Planalto Central (Figura 1). No condomínio San Diego foi instalado o projeto
Piloto I e no Condomínio Privê Lago Norte foi instalado o Projeto Piloto II. Geologicamente, nas duas áreas ocorrem rochas atribuídas ao Grupo Paranoá que é representado por uma sucessão psamo-pelito-carbonatada com onze formações, das quais sete ocorrem no polígono do Distrito Federal (Campos et al., 2013). 

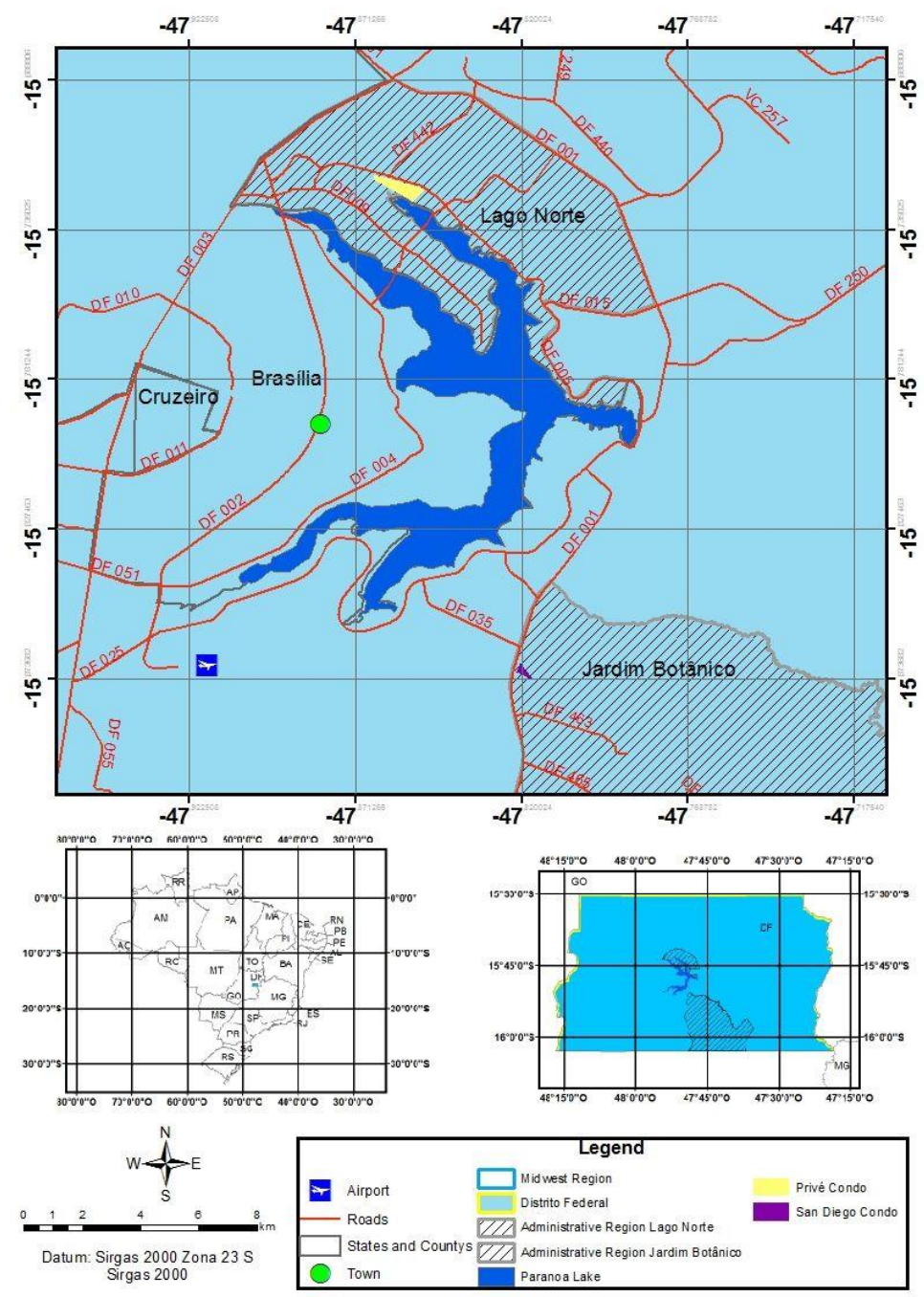

Figura 1 - Mapa de localização das áreas de estudo.

No Condomínio San Diego ocorrem quartzitos do topo da Formação Ribeirão Contagem (Figura 2a) em contato com metarritmitos da Formação Córrego do Sansão (Figura 2b). No Condomínio Privê o substrato é exclusivamente composto por ardósias da Formação Ribeirão do Torto (Figura 2c).

No Condomínio San Diego foram identificados dois tipos principais de materiais residuais oriundos de pedogênese in situ: plintossolo litoplíntico concrecionário, poroso, desenvolvido a partir do intemperismo de metarritmitos e neossolos quartzarênicos desenvolvidos a partir da alteração de quartzitos médios. No condomínio Privê ocorrem latossolos vermelhos nas áreas aplainadas e cambissolos nas áreas de maior declividade (Nunes, 2017).

A área de estudo do Projeto Piloto I está inserida no contexto hidrogeológico que inclui aquíferos rasos associados ao Sistema $\mathbf{P}_{1}$, com grande espessura e elevada condutividade hidráulica e no Domínio Fraturado caracterizado pelo Subsistema $\mathbf{R}_{\mathbf{3}} / \mathbf{Q}_{\mathbf{3}}, \quad$ Sistema Paranoá
(Campos, 2004). A recarga dos aquíferos desse domínio se dá através do fluxo vertical e lateral de águas de infiltração a partir das chuvas. Constitui região de recarga natural regional da unidade hidrográfica do Ribeirão Taboca.

A área de estudo do Projeto Piloto II, no Condomínio Privê Lago Norte, está inserida no contexto hidrogeológico de aquíferos rasos caracterizados pelo Sistema $\mathbf{P}_{4}$, meio intergranular representado por solos rasos (cambissolos e neossolos litólicos) e saprolitos espessos, comumente desenvolvidos de rochas pelíticas. No Domínio Fraturado o aquífero é representado pelo Subsistema $\mathbf{A}$, com vazões médias da ordem de $4,5 \mathrm{~m}^{3} / \mathrm{h}$ (Campos, 2004).

O clima é caracterizado como a média das condições climáticas do Distrito Federal e é marcado pela forte sazonalidade, com duas estações contrastantes. O período entre maio e setembro é evidenciado pela baixa taxa de precipitação, baixa nebulosidade, alta taxa de evaporação, com baixas umidades relativas diárias. O período entre outubro e abril apresenta 
padrões distintos, sendo que os meses de precipitação anual. A precipitação média anual é dezembro a março concentram $47 \%$ da da ordem de $1500 \mathrm{~mm}$.

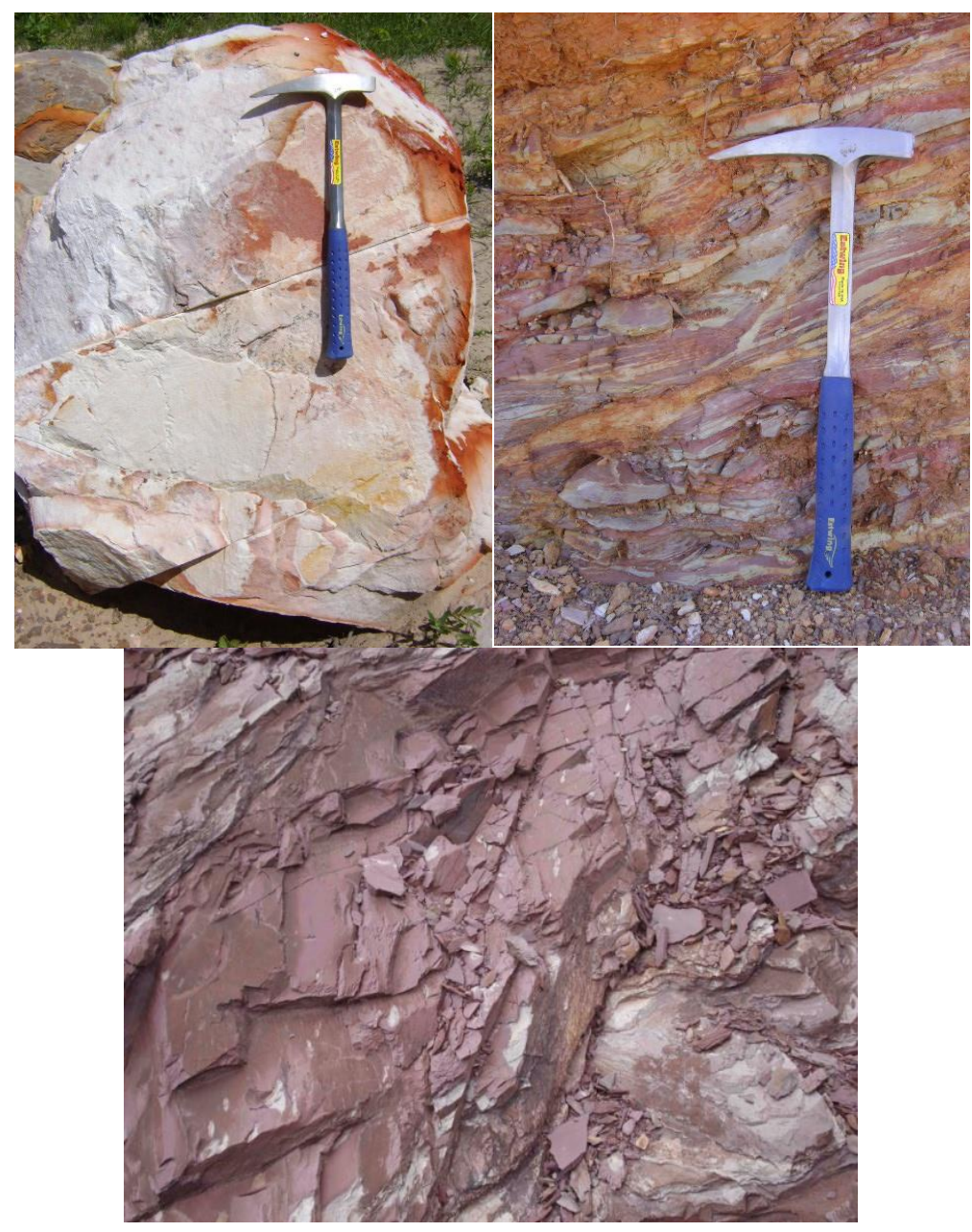

Figura 2 - a) Bloco de quartzito branco com manchas de oxidação, exposto a partir das obras de implantação de condomínios, b) Exposição de fácies pelítica de metarritmito arenoso, exposto próximo à área de instalação de sistema piloto de recarga artificial no Condomínio San Diego e c) Exposição de ardósia roxa da Formação Ribeirão do Torto do Grupo Paranoá que ocorre no Condomínio Privê Lago Norte.

A implantação desses condomínios residenciais edificados fora do alcance das redes de coleta e tratamento da Companhia de Saneamento Ambiental de Brasília - CAESB com ocupações de elevada densidade humana que desde os anos 1990 infiltram os efluentes na zona não saturada dos aquíferos levou à degradação dos mananciais superficiais e subterrâneos o que exige instrumentos de gestão que possam melhorar a disponibilidade e a qualidade dos recursos hídricos.

Para o Setor Habitacional Jardim Botânico todas as feições naturais resultam em área de elevado risco a contaminação. $O$ relevo é relativamente plano com declividade inferior a $8 \%$ em toda a porção anterior à borda da chapada; os solos são rasos e apresentam elevada condutividade hidráulica, a zona não saturada é rasa a muito rasa, localmente ocorrem fraturas saturadas a 2,4 metros de profundidade e os solos são pobres em matéria orgânica e muito arenosos.

Dessa forma os efluentes gerados no saneamento in situ não são atenuados na zona não saturada e a contaminação é rápida.

No Condomínio San Diego o risco de contaminação é muito elevado por se tratar de solos arenosos sobre quartzitos e metarritmitos arenosos. No Condomínio Privê Lago Norte o risco é minimizado por se tratar de solos argilosos, entretanto, com o tempo e persistência da carga a contaminação deverá alcançar a zona saturada.

Resultados de análises químicas de águas de poços tubulares profundos operados pela CAESB (amostragem em julho / agosto de 2007) apresentam valores de alerta para nitrato, cloro e Fe total em poços de condomínios da região do Setor Habitacional Jardim Botânico. Resultados de $\mathrm{pH}$ e coliformes totais apresentam valores acima do máximo permissível em alguns poços da região. 


\section{MATERIAIS E MÉTODOS}

A metodologia consistiu, inicialmente, no diagnóstico da área e seu entorno imediato, mediante a caracterização geológica, geomorfológica e pedológica, bem como, a caracterização dos aquíferos.

Dois sistemas de recarga artificial foram construídos: sistema de Recarga Piloto I (no Condomínio San Diego) e Sistema de Recarga Piloto II (Condomínio Privê Lago Norte), ambos visando à recarga de aquíferos fraturados, respectivamente, Subsistema $\mathbf{R}_{\mathbf{3}} / \mathbf{Q}_{3}$ e Subsistema A.

Os sistemas de recarga devem se localizar a uma distância mínima de 3 metros do poço produtor em que serão realizadas as coletas de amostras de água e devem ser implantados distantes de edificações, muros, residências. Inicialmente as caixas foram alimentadas por água potável obtida de caminhões pipa para se ter maior controle dos volumes de injeção e facilitar os cálculos e dimensionamento dos sistemas de recarga artificial propostos. Posteriormente as caixas deverão ser alimentadas por água de chuva captada em coberturas de residências nos meses de maior índice pluviométrico, no sentido de aproveitar o excedente hídrico das precipitações, principalmente entre os meses de novembro e março.

Os sistemas deverão ser construídos preferencialmente nas áreas verdes dos lotes (geralmente áreas com coberturas de grama) o mais afastado possível das edificações para evitar eventuais problemas geotécnicos, como recalques em fundações, saturação em solos colapsíveis, entre outros.

Para os dois projetos foi aplicado o sistema indireto de recarga artificial por caixas de infiltração, tipo Cadamuro (Cadarmuro, 2002, Cadamuro et al., 2002 e Cadamuro \& Campos, 2005) para locais de solos ou aterros permeáveis.

\section{RESULTADOS}

\section{Avaliação da Contaminação dos Aquíferos}

Foram coletadas amostras de água em seis pontos dos diferentes canais formados pelas nascentes da borda da chapada (Figura 3) que se juntam para formar o Ribeirão Taboca. Essa amostragem teve como objetivo verificar a extensão da pluma de contaminação, pois essas nascentes são pontos de descargas dos aquíferos à montante (Tabela1). Os resultados obtidos para o íon nitrato (Tabela 1) mostram que a contaminação alcançou as nascentes da borda da chapada, exutórios das águas infiltradas na região dos condomínios do Jardim Botânico. A condutividade elétrica também se mostra anômala nos pontos 3,5 e 6 .

As análises in situ das águas de dois poços tubulares profundos internos ao Condomínio San Diego (Tabela 2) apresentaram valores que demonstram contaminação do aquífero. Os dados mostram níveis para o íon nitrato acima do limite de potabilidade para os poços 2 e 3 e teores elevados para a amônia nos três poços.

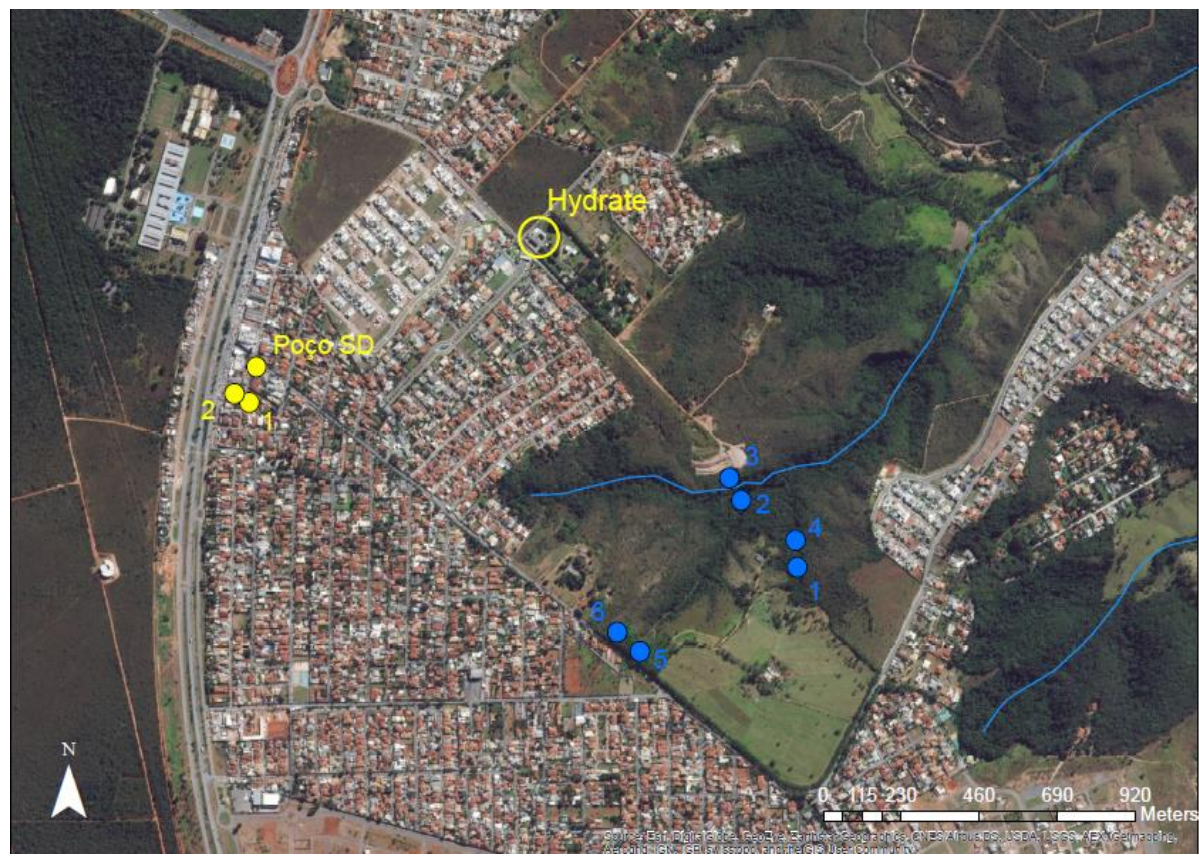

Figura 3 - Localização dos poços amostrados no Condomínio San Diego (em amarelo) e das nascentes amostradas que fluem para o Ribeirão Taboca (em azul). 
Tabela 1 - Resultados de análise química in situ de águas das nascentes do Ribeirão Taboca.

\begin{tabular}{|c|c|c|c|c|c|c|c|c|c|}
\hline \multirow[b]{2}{*}{ PONTOS } & \multirow[b]{2}{*}{ DATA } & \multirow[b]{2}{*}{ HORA } & \multicolumn{7}{|c|}{ PARÂMETROS - NASCENTES DO RIBEIRÃO TABOCA } \\
\hline & & & $\mathrm{T}\left({ }^{\circ} \mathrm{c}\right)$ & $\mathrm{OD}(\%)$ & $\begin{array}{c}\mathrm{OD} \\
(\mathrm{mg} / \mathrm{l})\end{array}$ & $\begin{array}{c}\text { TDS } \\
(\mu \mathrm{S} / \mathrm{cm})\end{array}$ & $\mathrm{C}(\mu \mathrm{S} / \mathrm{cm})$ & $\begin{array}{c}\mathrm{N} \mathrm{NH}^{+}{ }_{4-} \\
(\mathrm{mg} / \mathrm{l})\end{array}$ & $\begin{array}{c}\mathrm{N} \mathrm{NO}_{4}{ }^{+}{ }_{3-} \\
(\mathrm{mg} / \mathrm{l})\end{array}$ \\
\hline 1 & $12 / 05 / 2016$ & $10: 32$ & 18,4 & 54,6 & 5,13 & 6,8 & 6,0 & 0,06 & 0,20 \\
\hline 2 & $12 / 05 / 2016$ & $10: 47$ & 19,0 & 56,5 & 5,21 & 7,7 & 7,4 & 0,06 & 0,40 \\
\hline 3 & $04 / 09 / 2016$ & $10: 23$ & 23,1 & 44,8 & 3,83 & 145,2 & 141,00 & 0,10 & 1,10 \\
\hline 4 & $04 / 09 / 2016$ & 09:56 & 23,4 & 36,3 & 3,09 & 7,8 & 7,5 & 0,09 & 0,12 \\
\hline 5 & $04 / 09 / 2016$ & $11: 15$ & 22,7 & 45,5 & 3,92 & 95,4 & 91,2 & 0,05 & 0,27 \\
\hline 6 & $04 / 09 / 2016$ & $11: 17$ & 23,4 & 42,4 & 3.61 & 95,3 & 92,5 & 0,02 & 0,68 \\
\hline
\end{tabular}

Tabela 2 - Resultados de análise in situ de águas dos poços 1 e 2 (internos) do Condomínio San Diego.

\begin{tabular}{|c|c|c|c|c|c|c|c|c|c|c|}
\hline \multirow[b]{2}{*}{ POÇO } & \multirow[b]{2}{*}{ DATA } & \multirow[b]{2}{*}{ HORA } & \multicolumn{8}{|c|}{ PARÂMETROS-POÇOS 1 e 2} \\
\hline & & & $\mathrm{T}\left({ }^{\circ} \mathrm{c}\right)$ & $\begin{array}{l}\text { OD } \\
(\%)\end{array}$ & $\begin{array}{c}\mathrm{OD} \\
(\mathrm{mg} / \mathrm{l})\end{array}$ & $\begin{array}{c}\text { TDS } \\
(\mu \mathrm{S} / \mathrm{cm})\end{array}$ & $\mathrm{C}(\mu \mathrm{S})$ & $\underset{(\mathrm{mg} / \mathrm{l})}{\mathrm{N} \mathrm{NH}^{+}}$ & $\begin{array}{c}\mathrm{N} \mathrm{NO}_{4}^{+}{ }_{3-} \\
(\mathrm{mg} / \mathrm{l})\end{array}$ & $\mathrm{NE}$ \\
\hline 1 & $27 / 09 / 2016$ & 13:46 & 26,6 & 2,27 & 28,3 & 336,6 & 346,8 & 4,69 & 6,12 & $8 \mathrm{~m}$ \\
\hline 2 & $27 / 09 / 2016$ & 13:56 & 26,6 & 1,78 & 22,1 & 467,3 & 478,8 & 5,31 & 10,34 & $13 \mathrm{~m}$ \\
\hline 2 & $27 / 09 / 2016$ & 15:02 & 27,3 & 2,63 & 33,0 & 474,0 & 492,4 & 4,3 & 12,91 & $13 \mathrm{~m}$ \\
\hline
\end{tabular}

Os resultados para o nitrato apresentados na Tabela 3 para as águas avaliadas do poço San Diego mostram uma contaminação persistente com valores de nitrato variando de 0,60 a 1,99 $\mathrm{mg} / \mathrm{L}$, considerando que os valores de background para este subsistema aquífero são da ordem 0,04 .

Os reduzidos valores de amônia indicam que a contaminação é persistente e ocorreu a maior tempo, pois a amônia já se encontra oxidada para a formação do nitrato.

\section{Capacidade Máxima de Infiltração Projeto Piloto I}

\section{Tempo de Chegada das Águas}

O objetivo dos ensaios hidráulicos realizados nos Projetos de Recarga Piloto I e II foi no sentido de se obter a capacidade máxima de infiltração na região do Condomínio San Diego e Condomínio Privê I. Os volumes injetados e as vazões de infiltração no poço do Projeto Piloto I são apresentados na Tabela 4.

O ensaio no Condomínio Privê foi realizado utilizando uma vazão média de $1000 \mathrm{~L} / \mathrm{h}$. Após cerca de 1 hora observou-se um acréscimo no valor da condutividade elétrica que permaneceu se elevando até o final do ensaio, ou seja, por mais 6 horas e 45min (Tabela 5).

Os dados apresentados no gráfico (Figura 4) mostram uma variação de quase $10 \mathrm{~m}$ de rebaixamento do período de janeiro até outubro/2016 com queda acentuada no período de estiagem, ou seja, de abril a agosto.

Tabela 3 - Resultados de análise in situ de águas do poço do Condomínio San Diego.

\begin{tabular}{c|c|c|c|c|c|c|c}
\hline \multirow{2}{*}{ DATA } & \multirow{2}{*}{ HORA } & \multicolumn{7}{|c}{ PARÂMETROS-POÇO SD 1 } \\
\cline { 3 - 8 } & & $\mathrm{T}\left({ }^{\circ} \mathrm{c}\right)$ & $\mathrm{OD}(\%)$ & $\mathrm{OD}(\mathrm{mg} / \mathrm{l})$ & $\mathrm{TDS}(\mu \mathrm{S} / \mathrm{cm})$ & $\mathrm{N} \mathrm{NH}^{+}{ }_{4}(\mathrm{mg} / \mathrm{l})$ & $\mathrm{N} \mathrm{NO}_{4}{ }^{+}{ }_{3}(\mathrm{mg} / \mathrm{l})$ \\
\hline $15 / 05 / 2016$ & $11: 00$ & 24,6 & 27,9 & 2,32 & 112,5 & 0,13 & 1,21 \\
\hline $15 / 05 / 2016$ & $13: 00$ & 25,8 & 30,6 & 2,49 & 109,0 & 0,03 & 0,99 \\
\hline $09 / 06 / 2016$ & $11: 30$ & 20,6 & 64,5 & 5,8 & 91,2 & 0,14 & 0,85 \\
\hline $12 / 06 / 2016$ & $11: 00$ & 23,9 & 37,0 & 3,14 & 97,6 & 0,02 & 1,16 \\
\hline $16 / 09 / 2016$ & $10: 00$ & 25,5 & 42,9 & 3,34 & 95,7 & 0,07 & 1,60 \\
\hline $18 / 09 / 2016$ & $11: 00$ & 24,4 & 34,2 & 2,86 & 94,4 & 0,03 & 1,86 \\
\hline $26 / 09 / 2016$ & $10: 00$ & 24,3 & 36,0 & 3,02 & 96,9 & 0,08 & 0,73 \\
\hline $27 / 09 / 2016$ & $16: 15$ & 24,5 & 35,9 & 3,00 & 95,4 & 0,04 & 1,29 \\
\hline $10 / 10 / 2016$ & $10: 04$ & 24,7 & 34,7 & 2,88 & 96,2 & 0,05 & 0,95 \\
\hline $11 / 10 / 2016$ & $08: 29$ & 24,0 & 37,4 & 3,15 & 106,6 & 0,05 & 1,94 \\
\hline $12 / 10 / 2016$ & $11: 12$ & 24,5 & 36,5 & 3,05 & 101,5 & 0,04 & 1,99 \\
\hline $13 / 10 / 2016$ & $08: 47$ & 23,9 & 37,5 & 3,16 & 99,3 & 0,07 & 1,42 \\
\hline $14 / 10 / 2016$ & $16: 06$ & 25,1 & 31,7 & 2,61 & 98,1 & 0,07 & 0,70 \\
\hline $15 / 10 / 2016$ & $12: 12$ & 25,0 & 36,2 & 2,99 & 99,7 & 0,06 & 1,01 \\
\hline $16 / 10 / 2016$ & $08: 49$ & 25,2 & 32,7 & 2,69 & 96,8 & 0,07 & 1,21 \\
\hline $17 / 10 / 2016$ & $08: 13$ & 24,5 & 34,2 & 2,85 & 95,2 & 0,07 & 1,06 \\
\hline $31 / 10 / 2016$ & $14: 53$ & 26,1 & 39,6 & 3,21 & 99,0 & 0,00 & 1,73 \\
\hline
\end{tabular}

São Paulo, UNESP, Geociências, v. 39, n. 1, p. 127 - 137, 2020 
Tabela 4 - Dados dos volumes injetados e vazão média no Projeto Piloto I - Condomínio San Diego.

\begin{tabular}{c|c|c}
\hline Data & Volume Injetado $(\mathbf{L})$ & Vazão Média (L/h) \\
\hline $12 / 05 / 2016$ & 4.500 & 3.000 \\
\hline $09 / 06 / 2016$ & 5.000 & 2.500 \\
\hline $16 / 09 / 2016$ & 7.000 & 5.904 \\
\hline $26 / 09 / 2016$ & 7.000 & 2.800 \\
\hline $10 / 10 / 2016$ & 15.000 & 3.464 \\
\hline
\end{tabular}

Tabela 5 - Resultados das análises feitas na água do poço escavado do Projeto Piloto II. O valor da CE desde o início da injeção variou entre 78,6 até $104,8 \mu \mathrm{S}$.

\begin{tabular}{|c|c|c|c|c|c|c|c|}
\hline \multirow{2}{*}{$\frac{\text { 08/10/2016 }}{\text { HORA }}$} & \multicolumn{3}{|c|}{ PARÂMETROS } & \multirow{2}{*}{$\begin{array}{c}08 / 10 / 2016 \\
\text { HORA }\end{array}$} & \multicolumn{3}{|c|}{ PARÂMETROS } \\
\hline & $\mathrm{T}\left({ }^{\circ} \mathrm{c}\right)$ & $\mathrm{PH}$ & $\mathrm{CE}(\mu \mathrm{S})$ & & $\mathrm{T}\left({ }^{\circ} \mathrm{c}\right)$ & $\mathrm{PH}$ & $\mathrm{CE}(\mu \mathrm{S})$ \\
\hline $09: 55$ & 23,5 & 8,4 & 80,6 & $13: 55$ & 24,3 & 8,28 & 103,2 \\
\hline $10: 10$ & 23,6 & 8,48 & 78,6 & $14: 10$ & 24,3 & 8,36 & 103,5 \\
\hline $10: 25$ & 24,1 & 8,54 & 78,9 & $14: 25$ & 25 & 8,47 & 101,9 \\
\hline $10: 40$ & 23,9 & 8,37 & 81,7 & $14: 40$ & 24,7 & 8,6 & 100,1 \\
\hline $10: 55$ & 23,9 & 8,35 & 83,9 & $14: 55$ & 24,6 & 8,61 & 102,3 \\
\hline $11: 10$ & 23,9 & 8,36 & 87 & $15: 10$ & 24,8 & 8,49 & 101,3 \\
\hline $11: 25$ & 23,9 & 8,34 & 89,9 & $15: 25$ & 24,8 & 8,45 & 101,8 \\
\hline $11: 40$ & 23,7 & 8,22 & 91,5 & $15: 40$ & 24,6 & 8,37 & 102 \\
\hline $11: 55$ & 23,9 & 8,28 & 97,6 & $15: 55$ & 24,2 & 8,35 & 102,2 \\
\hline $12: 10$ & 23,9 & 8,3 & 100,4 & $16: 10$ & 24,1 & 8,35 & 104,8 \\
\hline $12: 25$ & 23,9 & 8,31 & 100,9 & $16: 25$ & 23,9 & 8,44 & 104,8 \\
\hline $12: 40$ & 23,9 & 8,31 & 103,1 & $16: 40$ & 23,9 & 8,32 & 104,6 \\
\hline $12: 55$ & 24 & 8,33 & 102,9 & $16: 55$ & 23,7 & 8,36 & 104,8 \\
\hline $13: 10$ & 23,9 & 8,28 & 103,4 & $17: 10$ & 23,5 & 8,29 & 105,3 \\
\hline $13: 25$ & 23,9 & 8,27 & 103,6 & $17: 25$ & 23,5 & 8,32 & 104,7 \\
\hline $13: 40$ & 24,1 & 8,29 & 103,3 & $17: 40$ & 23,5 & 8,2 & 104,8 \\
\hline
\end{tabular}

\begin{tabular}{ccccccc}
15,32 & 15,23 & 14,87 & 16,31 & 23,72 & 24,61 & 25,14 \\
\hline JAN & FEV & MAR & ABR & AGO & SET & OUT
\end{tabular}

Figura 4 - Variação do NA do poço do Condomínio San Diego de Janeiro a Outubro de 2016.

Cálculo dos Volumes Estimados de Recarga Artificial Potencial no Condomínio San Diego

Foram identificados 280 lotes que apresentam as condições para instalação de caixas de infiltração, portanto são passíveis de fazer recarga das águas da chuva captadas a partir dos telhados e direcionadas para as caixas de infiltração. Na sequência foram delimitadas as coberturas das construções e então se obteve um valor total de $\mathbf{6 1 . 4 2 3} \mathbf{m}^{2}$ para as áreas cobertas dos lotes (Figura 5).

Para os cálculos dos volumes de recarga potencial, utilizou-se a fórmula:

$\mathbf{R p s D}=$ PP Liq $x$ Área de coberturas, onde:

RpSD - Recarga artificial potencial no Condomínio San Diego

PP Liq - Precipitação pluviométrica anual líquida $=1000 \mathrm{~mm} /$ ano (considerando perdas por evapotranspiração e o fluxo interno);
Área de coberturas - Total das áreas dos polígonos das coberturas das construções.

$\mathbf{R p}=1000 \mathrm{~mm} /$ ano $\times 61.423,56 \mathrm{~m}^{2}=1 \mathrm{~m} / \mathrm{ano}$ x $61423,56 \mathrm{~m}^{2}=\mathbf{6 1 . 4 2 3 , 5 6} \mathrm{m}^{3} / \mathbf{a n o}$.

Considerando que nem todos os lotes tenham suas caixas de infiltração construídas ou tenham viabilidade técnica para a instalação dos sistemas de recarga serão considerados dois cenários realistas para a máxima recarga na região: 40 e $60 \%$ da área de cobertura de residências. Assim, no primeiro cenário seria possível adicionar por recarga artificial um volume da ordem de 24.569 $\mathbf{m}^{3} /$ ano. Para um cenário mais otimista, considerando $60 \%$ de implantação dos sistemas de recarga artificial, o volume potencial de recarga poderia alcançar $36.854 \mathrm{~m}^{3} / \mathbf{a n o}$.

Cálculo dos Volumes Estimados de Recarga Artificial Potencial no Condomínio Privê

Foram identificados 422 lotes que apresentam 
as condições para instalação de caixas de infiltração, portanto são passíveis de fazer recarga das águas da chuva captadas a partir dos telhados e direcionadas para as caixas de infiltração. Na sequência foram delimitadas por polígonos, as coberturas das construções e então

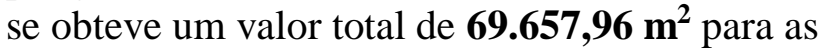
áreas cobertas dos lotes (Figura 6).

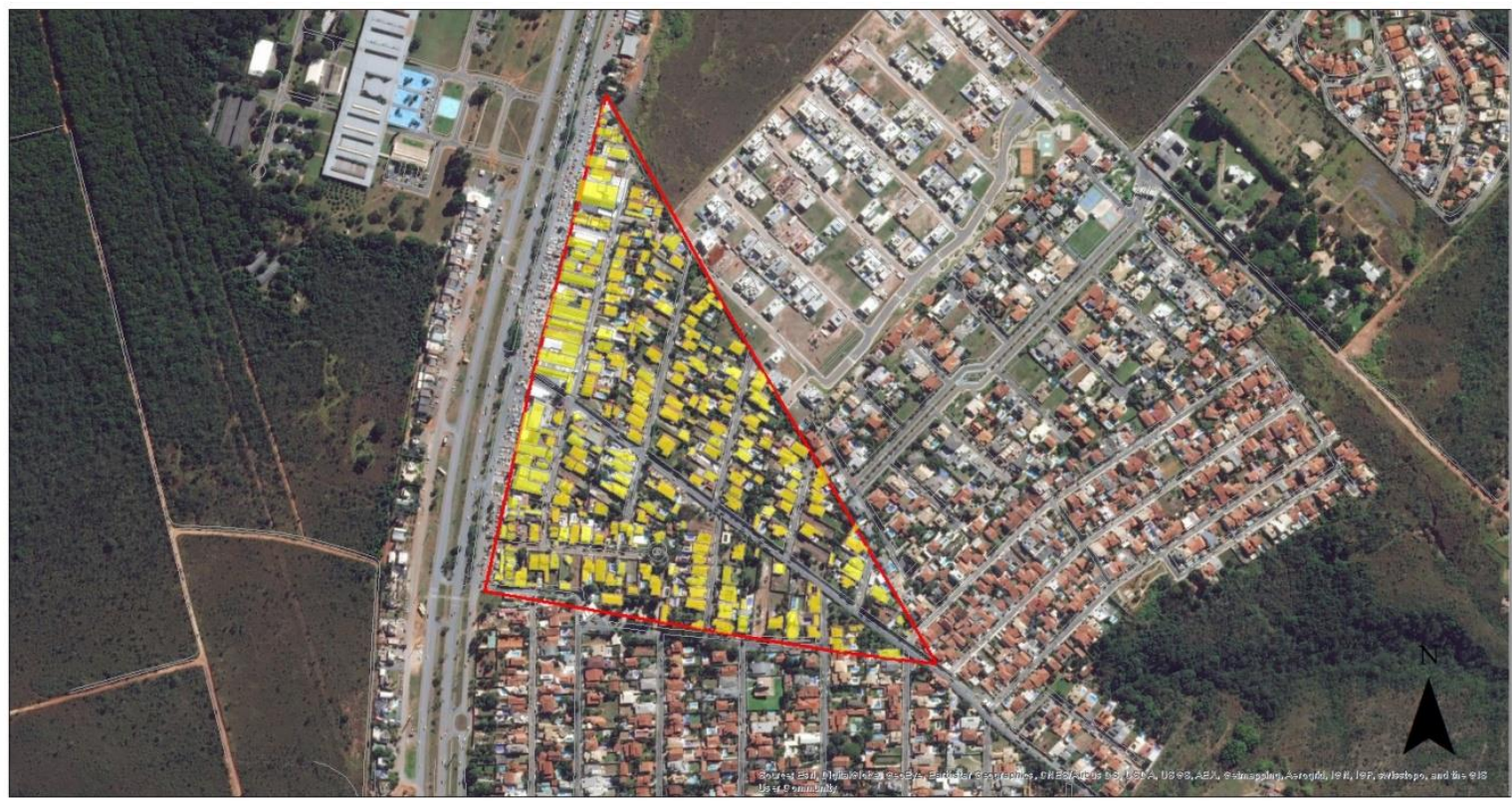

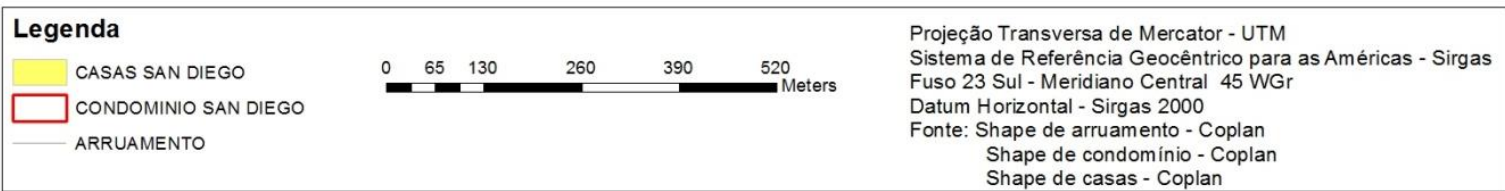

Figura 5 - Imagem da poligonal do Condomínio San Diego mostrando as coberturas das residências com sombreamento em amarelo.

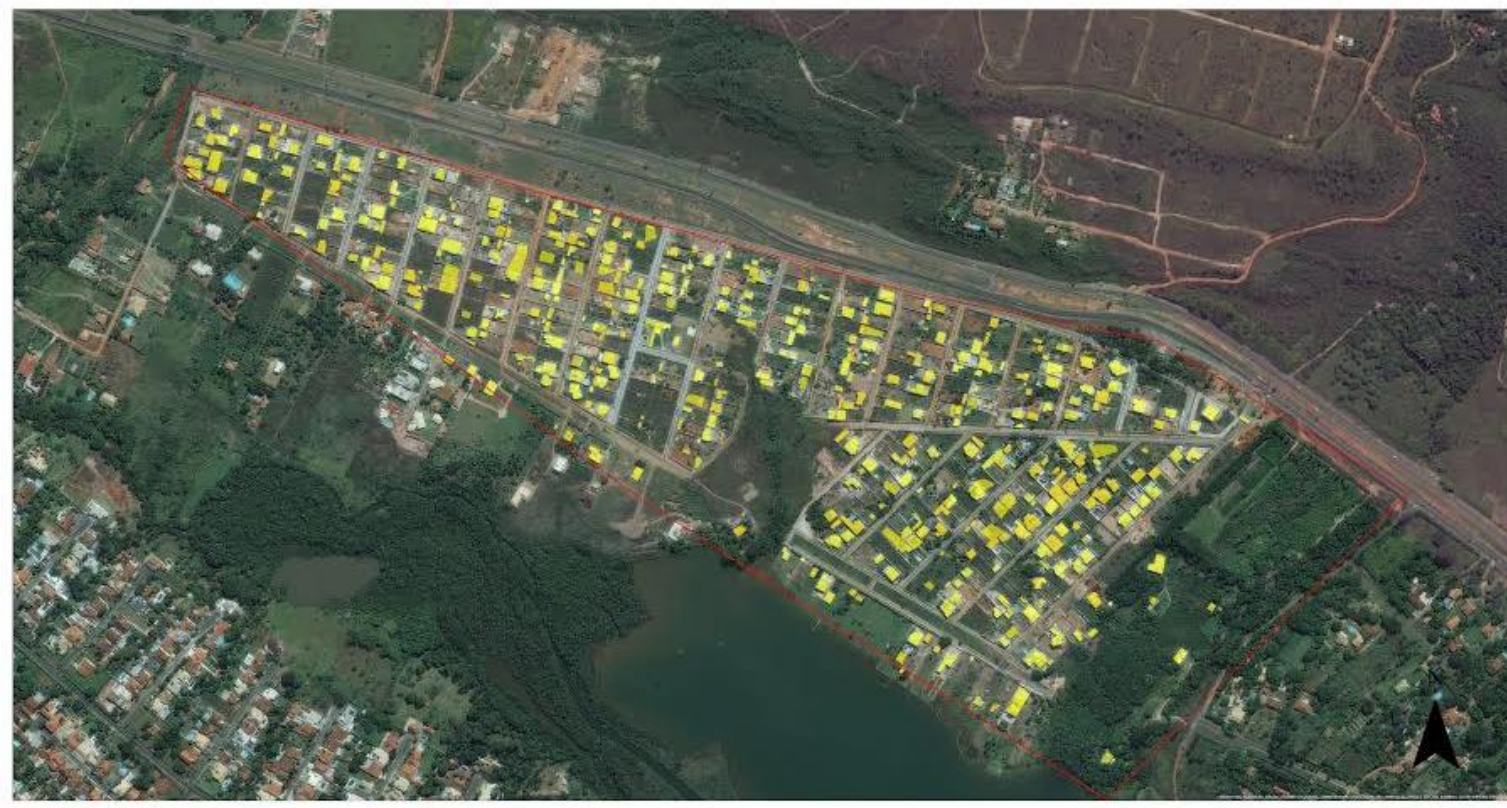

\section{Legenda}

ARRUAMENTO

CONDOMINIO

CASAS PRIVE
Projeçäo Transversa de Mercator - UTM

Sistema de Referência Geocêntrico para as Américas - Sirgas Fuso 23 Sul - Meridiano Central 45 WG

800

Datum Horizontal - Sirgas 2000

Shape de condominio - Coplan

Figura 6 - Imagem da poligonal do Condomínio Privê Lago Norte mostrando as coberturas de residências em amarelo.

Para os cálculos dos volumes de recarga potencial, utilizou-se a equação:
Rpp = PP Liq $x$ Área de coberturas, onde:

Rpp - Recarga potencial Condomínio Privê; 
PP Liq - Precipitação pluviométrica anual líquida $=1000 \mathrm{~mm} / \mathrm{ano}$ (considerando as perdas por evapotranspiração e por fluxo interno);

Área de coberturas - Total das áreas dos polígonos das coberturas das construções.

$\mathbf{R p}=1000 \mathrm{~mm} / \mathrm{ano} \times 69.657,96 \mathrm{~m}^{2}=1 \mathrm{~m} / \mathrm{ano}$ x $69.657,96 \mathrm{~m}^{2}=\mathbf{6 9 . 6 5 7} \mathbf{~ m}^{3} /$ ano

Considerando que nem todos os lotes tenham suas caixas de infiltração construídas e que sejam inseridos nos projetos de recarga artificial, serão utilizados dois cenários: um percentual de $40 \%$ para se obter um volume mais conservador, ou

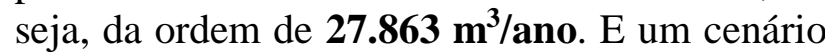
mais otimista, considerando que $60 \%$ dos lotes implantem o sistema de recarga artificial, o que resulta em um volume potencial de recarga de $41.794 \mathrm{~m}^{3} /$ ano.

\section{Estimativas de Reservas Renováveis e} Permanentes

\section{Reservas Renováveis - Projeto Piloto I}

Foram realizados os cálculos das reservas renováveis para a área permeável do Condomínio San Diego, utilizando-se a fórmula a seguir:

$\mathbf{R r q}=\mathbf{A p} \cdot \Delta \mathbf{h} . \mathbf{I}_{\mathbf{f i}}$

Onde:

Rrq - Reservas renováveis do $\mathrm{Q}_{3}$;

Ap - Área permeável $=20 \%$ da área total do Condomínio $=43.159,8 \mathrm{~m}^{2}$

$\Delta \mathbf{h}$ - Variação média do nível freático (2008 a 2016) $=9,06 \mathrm{~m}$

$\mathbf{I}_{\mathbf{f i}}$ - Índice de fraturas interconectadas do Subsistema $\mathbf{R}_{\mathbf{3}} / \mathbf{Q}_{\mathbf{3}}=3 \%$

Aplicando os valores acima na fórmula $\mathrm{Rr}=$ Ap . $\Delta$ h. I $\mathrm{I}_{\mathrm{fi}}$, tem-se:

$\mathbf{R r}=43.159,8 \times 9,06 \times 0,03=11.730 \mathrm{~m}^{3}$

$$
\mathbf{R r}=\mathbf{1 1 . 7 3 0} \mathbf{~ m}^{3} / \mathbf{a n o}
$$

\section{Reservas Renováveis - Projeto Piloto II}

Foram realizados os cálculos das reservas renováveis para a área permeável do Condomínio Prive, utilizando-se a fórmula abaixo:

$$
\begin{aligned}
& \mathbf{R}_{\mathbf{r A}}=\mathbf{A p} \times \mathbf{I}_{\mathbf{p D F}} \times \mathbf{I}_{\mathbf{f i}}=146.013 \mathrm{~m}^{2} \times 1,00.10^{-} \\
& { }^{3} \mathrm{~km} / \mathrm{ano} \times 0,05 \\
& \mathbf{R}_{\mathbf{r A}}=\mathbf{7 . 3 0 0} \mathbf{~ m}^{\mathbf{3}} / \mathbf{a n o} \\
& \text { Onde: }
\end{aligned}
$$

$\mathbf{R}_{\mathbf{r A}}$ - Reservas Renováveis do Subsistema A Ap - $20 \%$ da Área total do Condomínio Privê IpDF - Índice Pluviométrico médio Anual do DF (considerando perdas por evapotranspiração e o fluxo interno);

Ifi - Índice de fraturamento interconectado

Reservas Permanentes

Para o cálculo das reservas permanentes dos subsistemas: $\mathbf{R}_{\mathbf{3}} / \mathbf{Q}_{\mathbf{3}}$ e $\mathbf{A}$ foram utilizadas as seguintes equações:

$$
\begin{aligned}
& \mathrm{R}_{\mathbf{p Q}}=\mathbf{A}_{\mathrm{SD}} \times \mathbf{x} \text { b } \mathbf{x} \mathbf{I}_{\mathbf{f i}} \\
& \mathrm{R}_{\mathrm{pA}}=\mathbf{A P}_{\mathbf{P}} \times \mathbf{b} \times \mathbf{I}_{\mathbf{f i}} \\
& \text { Onde: }
\end{aligned}
$$

$\mathrm{R}_{\mathrm{pq}}$ - Reservas Permanentes do subsistema $\mathbf{R}_{3} / \mathbf{Q}_{3}$

$\mathrm{R}_{\mathrm{pA}}$ - Reservas Permanentes do Subsistema A

$\mathrm{A}_{\mathrm{SD}}$ - Área do Condomínio San Diego

AP - Área do Condomínio Privê

b - Espessura da zona saturada

$\mathrm{I}_{\mathrm{fi}}$ - Índice de fraturamento interconectado

Projeto Piloto de Recarga I - Condomínio San Diego

Subsistema $\mathbf{R}_{\mathbf{3}} / \mathbf{Q}_{\mathbf{3}} \quad \mathbf{1}=215.799,52 \mathrm{~m}^{2} \times 70 \mathrm{~m}$ $\mathrm{x} 0,035=528.708,82 \mathrm{~m}^{3}$;

Subsistema $\mathbf{R}_{\mathbf{3}} / \mathbf{Q}_{\mathbf{3}} \quad 2=215.799,52 \mathrm{~m}^{2}$ × $60 \mathrm{~m}$ x $0,02=258.959,42 \mathrm{~m}^{3}$;

Subsistema $\mathbf{R}_{\mathbf{3}} / \mathbf{Q}_{\mathbf{3}} \mathrm{T}=\mathbf{7 8 7 . 6 6 8 , 2 4} \mathbf{~ m}^{3}$.

Projeto Piloto de Recarga II - Condomínio Privê

Subsistema A $1=730.067 .12 \mathrm{~m}^{2}$ x $50 \mathrm{~m} \mathrm{x}$ $0,005=182.516,78 \mathrm{~m}^{3}$

Subsistema $\mathbf{A}_{2}=730.067 .12 \mathrm{~m}^{2}$ x $50 \mathrm{~m} \mathrm{x}$ $0,003=109.510,07 \mathrm{~m}^{3}$

Subsistema $A_{\text {T }}=\mathbf{2 9 2 . 0 2 6 , 8 5 ~ \mathbf { m } ^ { 3 }}$

\section{Análise Qualitativa dos Resultados}

Na região do Sistema de Recarga Piloto I, o modelo de circulação das águas subterrâneas proposto envolve três sistemas de fluxo hidrogeológico: fluxo rápido por higroscopia (setas pretas), fluxo interno (setas azuis) e fluxo em fratura (setas vermelhas). A Figura 7 apresenta os fluxos em duas dimensões, entretanto é necessário observar que o fluxo é um fenômeno tridimensional.

Para a área do Sistema de Recarga Piloto II, o modelo de circulação das águas subterrâneas envolve os mesmos três tipos de fluxos propostos para o Piloto I: fluxo rápido por higroscopia (setas pretas), fluxo interno (setas azuis) e fluxo em fratura (setas vermelhas). A Figura 8 mostra o padrão de fluxo bidimensional. Neste caso o fluxo no contato entre o aterro e o horizonte superficial natural é predominante.

\section{Análise Quantitativa dos Resultados}

Para o Sistema de Recarga Piloto I, Condomínio San Diego, considerando um Cenário1 no qual $40 \%$ dos lotes implantem a recarga artificial obtém-se um volume de 24.569,42 $\mathrm{m}^{3}$ por ano. Esse valor supera o cálculo realizado para recarga natural das 
reservas renováveis do Subsistema $\quad \mathbf{R}_{\mathbf{3}} / \mathbf{Q}_{\mathbf{3}}$ quando se obteve um volume $11.730,86 \mathbf{~ m}^{3}$ considerando um percentual de apenas $20 \%$ da área total do referido condomínio como área permeável, ou seja, passível de infiltração de águas da chuva. A soma desses dois volumes totaliza $36.300,28 \mathrm{~m}^{3}$ que anualmente realimentariam o sistema aquífero a partir da recarga natural e da recarga artificial nas caixas de infiltração construídas nesses lotes. Para o Cenário 2, mais otimista, considerou-se que $60 \%$ dos lotes realizem a recarga artificial resultando em um volume de reserva renovável potencial da ordem de $\mathbf{4 8 . 5 8 5 , 0} \mathbf{~ m}^{3}$.

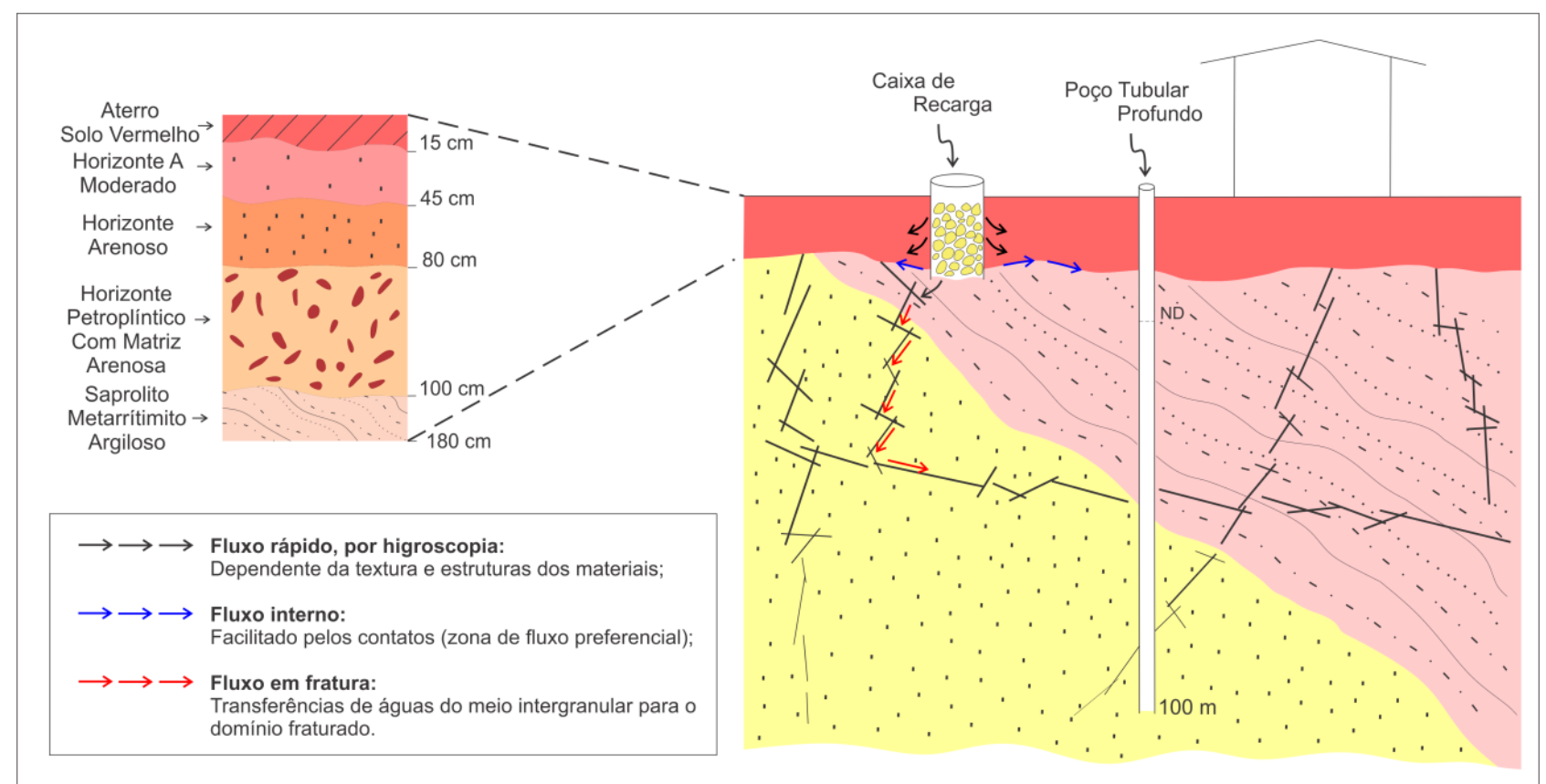

Figura 7 - Representação esquemática das condições de circulação das águas subterrâneas a partir de caixa de recarga artificial (Projeto de Recarga Piloto I).

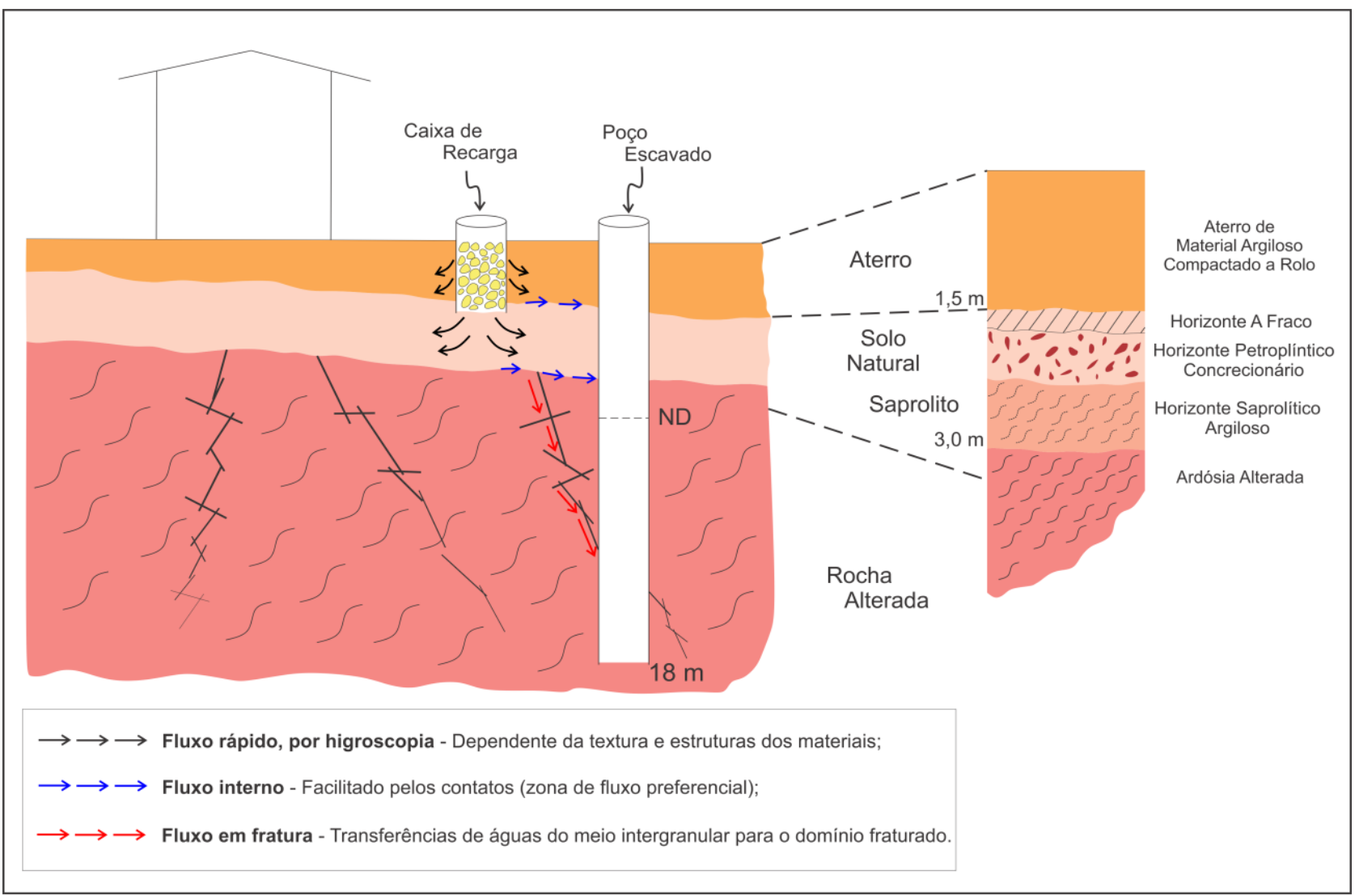

Figura 8 - Representação esquemática de modelo de circulação das águas subterrâneas proposto para o Projeto de Recarga Piloto II. 
Considerando que $40 \%$ das construções façam recarga artificial das águas da chuva em caixas de infiltração obteve-se um período da ordem de 21 anos como tempo necessário para eficiência da recarga e consequente diluição dos contaminantes e para um cenário em que $60 \%$ desenvolvam a recarga artificial obtém-se um período de tempo da ordem de 16 anos. Estas propostas de tempos médios para diluição consideram que, tanto as águas do aquífero freático, quanto as reservas do aquífero fraturado já estão contaminadas

Para o Sistema de Recarga Piloto II, a análise é semelhante, ou seja, considerando que $40 \%$ das construções façam a recarga por meio das caixas de infiltração obtém-se $\mathbf{2 7 . 8 6 3 , 0 2} \mathbf{~ m}^{3}$. Somando a esse valor de recarga potencial obtida pela utilização de caixas de infiltração ao volume das reservas reguladoras calculado para $\mathrm{o}$ Condomínio Privê de $\mathbf{7 . 3 0 0 , 6 7} \mathbf{~ m}^{3}$, obtém-se
35.163,69 $\mathrm{m}^{3}$ como recarga potencial para o Subsistema A, do Domínio Fraturado que ocorre no referido Condomínio. Considerando que $60 \%$ dos lotes construam suas caixas de infiltração e façam recarga somando o volume dessa recarga potencial de 41.794,54 $\mathrm{m}^{3}$ com o volume da recarga anual calculado para $20 \%$ da área permeável do Condomínio, $7.300,67 \mathrm{~m}^{3}$, obtém-

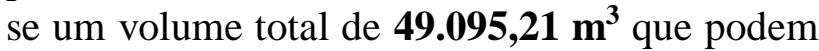
ser infiltrados e realimentar o Domínio Fraturado do Subsistema A.

Considerando os mesmos cenários citados, obtém-se para $40 \%$ das construções executando recarga artificial a partir das águas da chuva com qualidade de água potável, um período de tempo necessário de cerca de 10 anos e para $60 \%$ das construções fazendo recarga obtém-se um período de tempo de cerca de 7 anos para eficiência da recarga e diluição das cargas contaminantes.

\section{CONSIDERAÇÕES FINAIS}

Os resultados das análises do parâmetro nitrato na água coletada do poço SD 01 não apresentaram variação que demonstrasse alguma diluição desse contaminante como consequência da injeção de água por meio da caixa de infiltração. Este fato pode estar relacionado à ausência de conexão hidráulica entre o referido poço e a caixa de infiltração devido à ausência de fraturas, da posição do poço com relação às estruturas ou da declividade do topo rochoso. Embora a diluição não tenha sido constatada no poço monitorado, é fato que um grande volume de água foi infiltrado na caixa de infiltração, e que pelo menos em parte realimentou os aquíferos subjacentes.

Após o desenvolvimento dos estudos, integrando os dados sobre a hidrogeologia, solos, relevo, testes hidráulicos, alguns dados de hidroquímica, áreas ocupadas por coberturas de edificações, áreas verdes e distribuição de chuvas, as seguintes conclusões podem ser enumeradas:

- Os sistemas de recarga artificial propostos apresentam alta efetividade para induzir a infiltração de águas de chuvas coletadas nas coberturas de edificações em condomínios horizontais;

- Os resultados dos cálculos e estimativas de reservas realizados mostram que o volume de água que pode ser infiltrado para alimentar os aquíferos subjacentes por meio de recarga artificial é considerável, mesmo com a utilização de parâmetros subdimensionados;

- Os volumes potenciais de infiltração, considerando diferentes cenários, são relevantes e podem auxiliar na remediação in situ de aquíferos contaminados em prazos variáveis entre 5 e 15 anos dependendo do grau de adesão da população e do meio físico local;

- A eficiência da recarga artificial pode ser definida pela capacidade máxima de infiltração nos diferentes sistemas de recarga e varia conforme os diferentes controles do meio físico local. Sobre solos naturais arenosos e mais espessos a capacidade de recarga artificial é maior que para os casos de aterros com uso de solos argilosos;

- A região do Condomínio San Diego já tem os aquíferos contaminados pela infiltração dos efluentes. A contaminação foi constatada pelo monitoramento da qualidade das águas dos poços de abastecimento e pela verificação da presença de nitrato nas águas das nascentes que são exutórios destes aquíferos;

- No Condomínio Privê Lago Norte a contaminação ainda não foi confirmada, entretanto, como o saneamento é realizado in situ na forma de fossas e sumidouros, se considera que a contaminação é apenas uma questão de tempo para que alcance a zona saturada do aquífero fraturado representado pelo Subsistema A do Sistema Paranoá; 
- No sistema piloto instalado no Condomínio San Diego não se teve a confirmação de que as águas infiltradas nos testes hidráulicos alcançaram o poço tubular profundo situado na sua adjacência. Entretanto, a eficiência do sistema não pode ser questionada uma vez que as águas infiltradas devem, em sua maioria, alcançar a zona saturada dos aquíferos fraturados subjacentes;

- No Condomínio Privê a água que é direcionada para a caixa de recarga inicia o gotejamento para o poço escavado (cisterna) localizado a cerca de 2 metros em cerca de uma hora após o início da infiltração.

\section{REFERÊNCIAS}

CADAMURO, A.L.M. Proposta, Avaliação e Aplicabilidade de Técnicas de Recarga Artificial em Aquíferos Fraturados para Condomínios Residenciais do Distrito Federal Brasília, 2002. 130p. Dissertação (Mestrado), Instituto de Geociências, Universidade de Brasília.

CADAMURO, A.L.M., CAMPOS, J.E.G., TRÖGER, U. Artificial recharge in fractured rocks? An example from the Federal District of Brazil for the sustainability of the system. In: INTER. SYMP. ON ARTIFICIAL RECHARGE, 4, Adelaide. Proceedings... Adelaide, 2002, v. 1, p. 56-60.

CADAMURO, A.L.M. \& CAMPOS, J.E.G. Recarga Artificial de Aquíferos Fraturados no Distrito Federal: uma Ferramenta para a Gestão dos Recursos Hídricos. Revista Brasileira de Geociências, v. 35, n. 1, p. 89-98, 2005.

CAMPOS, J.E.G. Hidrogeologia do Distrito Federal: subsídios para a gestão dos recursos hídricos subterrâneos. Revista Brasileira de Geociências, v. 34, n. 1, p. 41-48, 2004.
CAMPOS, J.E.G.; DARDENE, M.A.; FREITAS-SILVA, F.H.; MARTINS-FERREIRA, M.A.C. Geologia do Grupo Paranoá na Porção Externa da Faixa Brasília. Brazilian Journal Geology, v. 43, n. 3, p. 461-476. 2013.

EMBRAPA. Mapa de solos do Distrito Federal (1:100.000). Brasília: EMBRAPA-EPI. - Serviço de Produção de Informação. 1978.

NUNES, M.D.X. Estudo da capacidade de infiltração em sistemas de recarga artificial de aquíferos contaminados no Distrito Federal. 2017. Brasília. 75p. Dissertação (Mestrado), Instituto de Geociências - Universidade de Brasília.

Submetido em 27 de junho de 2017 Aceito em 6 de dezembro 2019 